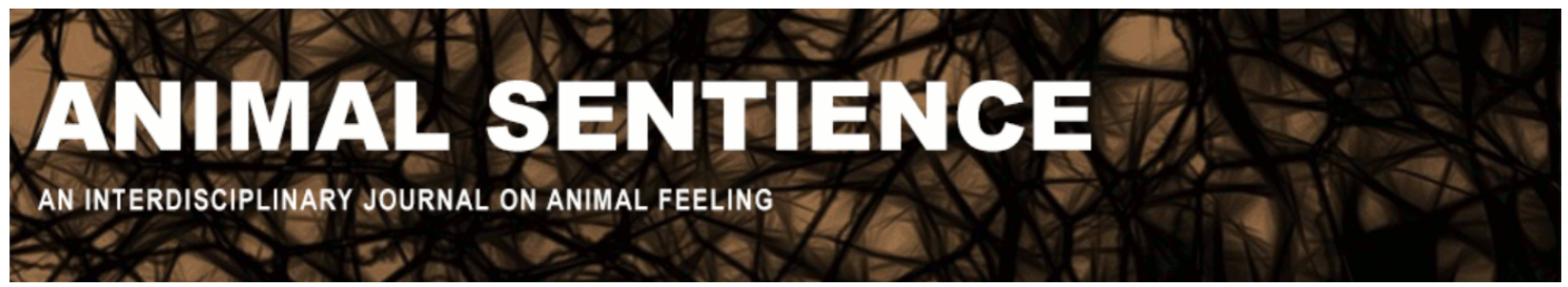

Toates, Frederick (2020) Covid-19, evolution, brains and psychology. Animal Sentience 30(21)

DOI: $10.51291 / 2377-7478.1654$

Date of submission: $2020-10-29$

Date of acceptance: $2020-10-29$

(c)

This article has appeared in the journal Animal

Sentience, a peer-reviewed journal on animal

cognition and feeling. It has been made open access,

free for all, by WellBeing International and deposited

in the WBI Studies Repository. For more information,

please contact

wbisr-info@wellbeingintl.org.

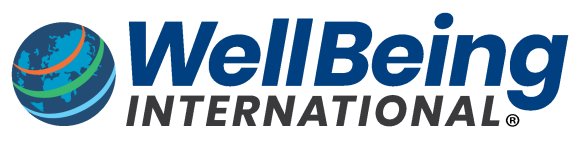

SOLUTIONS FOR PEOPLE, ANIMALS AND ENVIRONMENT 


\title{
Covid-19, evolution, brains and psychology
}

Commentary on Wiebers \& Feigin on Covid Crisis

\section{Frederick Toates}

Department of Life, Health and Chemical Sciences, Open University, UK.

\begin{abstract}
Attention needs to be directed to the processes that control behavior in humans and the adaptive problems that they solved in our early evolutionary environment. The evolutionary mismatch between the current environment and the human brain can yield important insights into the problems that beset us in the context of environmental degradation and nonhuman animal welfare.
\end{abstract}

Frederick Toates is Emeritus Professor of Psychology at the Open University in the UK. His research area is the theory of motivation and he pioneered incentive motivation theory. Website

\section{Introduction}

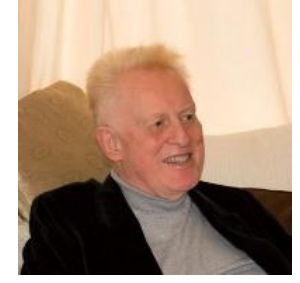

Wiebers \& Feigin's (2020) target article and the resultant commentaries are outstandingly good and highlight the many ways in which domesticated animals are living under suboptimal conditions, far removed from their evolutionary origins. However, what is missing is a discussion of the relevance of the evolution and the brains of one sentient species: humans. This species also lives far removed from its evolutionary origins, albeit not in an environment that inherently causes suffering. The implications of the departure of humans from their evolutionary roots are profound -- something implicitly recognized years back (Hardin, 1968).

2. The brain. The human brain contains an evolutionarily and developmentally old System 1 and an evolutionarily and developmentally new System 2 (Evans, 2011; Kahneman, 2011; Toates, 1997). System 1 is organized by largely subcortical brain mechanisms; it is relatively fast and reacts to physically present events at an often-unconscious level. It is oriented to the present. System 2 is organized in large part by cortical brain processes; it is relatively slow and involves purposive cognitive processes acting at a largely conscious level. It is oriented towards the future. Systems 1 and 2 can act in concert or in opposition. A strengthening of part of System 1 is seen in the incentive sensitization process described by Robinson and Berridge (1993). This was originally described for drug addiction but has later been applied more broadly. The authors coined the term 'wanting versus liking' and described how wanting can sometimes increase over time accompanied by no increase in liking, or even a decrease. This might explain the craving for material possessions.

System 1 has echoes of Skinner's reinforcement system, whereas System 2 has echoes of his rule-governed behavior (Skinner, 1965). In Freud's terms, System 1 has features in common with the id, whereas System 2 corresponds in some ways to the superego. In the context of the contemporary issues under discussion here, the problem can be described as behavior being largely 'present-oriented', i.e. under System 1 control, with an inadequacy of System 2 control.

3. The physical environment. In the early evolutionary environment, although infectious diseases were surely present, such things as air pollution, intensive agriculture and humanmade climate change were not. Hence humans have not acquired defense mechanisms to answer the challenges that they pose. In contemporary large urban centres, air pollution 
appears to compromise respiratory function and might well increase the risks associated with Covid-19. However, any individual defensive mechanisms (e.g. coughing, sneezing, rubbing eyes) are wholly inadequate. The solution calls for cultural transmission of information and collective action.

The private car pollutes compared to public transport but the pollution is collective rather than personal and is diffuse. Negative consequences such as effects on health of pollution are not immediate. The car offers convenience and privacy. The costs of public transport are felt immediately upon buying the ticket, whereas the benefits are largely diffuse, delayed and collective.

Road building encroaches upon the natural habitat of species but there are short-term gains in terms of profit for construction companies, employment and apparent faster journey times. The negative consequences, such as bringing more cars into towns, increasing congestion and pollution are impersonal, delayed and diffuse.

4. Diet. In the early environment, diet was not so energy-dense as now and food was obtained from hunting/gathering, with a necessary expenditure of energy. These days foods loaded with fats and sugars are readily available at minimal energy expenditure. Hence, we have a major obesity epidemic, which not only wastes enormous amounts of natural resources, requires industrialized farming and drains medical systems, but, it would seem, it also contributes to the seriousness of Covid-19 infections. It appears that today's diet offers very rapid positive reinforcement (System 1 control), with long-delayed negative consequences. System 2 control (resist fatty/sugary foods in the interests of long-term health) is no match for System 1.

5. The social environment. In our early evolution, altruism and empathy to conspecifics would probably have had a narrow range of expression (e.g. immediate tribe), certainly not a global reach. There would seem to be little adaptive advantage in feeling empathy for distant folk or non-human species. As Bloom (2017) has argued, in contemporary society, empathy tends to be parochial. A hurricane in Florida tends to cause more concern to folk in New York than does one in Bangladesh. Even within a single country, murder of children in Sandy Hook evokes a stronger response in Connecticut than when it happens in the South Side of Chicago. These days we need to be moved into action equally by tragedies anywhere in the world. A virus outbreak anywhere needs international cooperation and a rapid response unit. I would suggest that System 1 control is not adequate for the task; we need to cultivate System 2 control.

6. Conclusion. In three aspects of human-environment interaction, problems arise from the evolutionary mismatch of our brains and the demands of the present environment. Policies need to be informed by an understanding of brains and evolution. Behavior change might be best achieved by a parallel targeting of System 1 and 2. In terms of System 1 and in the spirit of B.F. Skinner, we need to alter the nature of reinforcers. searching for means of positively reinforcing environmentally desirable behavior. Here I would echo Lee's (2020) comment:

...the scale of the changes that are urgently needed will not be achieved by pleading, cajoling or shaming individuals.

In terms of System 2, we need to strengthen internal controls concerned with the environment. 


\section{References}

Bloom, P. (2017). Against Empathy: The Case for Rational Compassion. Random House.

Evans, J. S. B. (2011). Dual-process Theories of Reasoning: Contemporary issues and developmental applications. Developmental Review, 31(2-3), 86-102.

Hardin, G. (1968). The tragedy of the commons. Science 162: 1243-1248.

Kahneman, D. (2011). Thinking, Fast and Slow. Macmillan.

Lee, Kelley (2020) Rethinking global governance to address zoonotic disease risks: Connecting the dots. Animal Sentience 30(19)

Skinner, B. F. (1965). Science and Human Behavior. Simon and Schuster.

Toates, F. (1997). The interaction of cognitive and stimulus-response processes in the control of behaviour. Neuroscience \& Biobehavioral Reviews, 22(1), 59-83.

Wiebers, D. and Feigin, V. (2020) What the COVID-19 crisis is telling humanity. Animal Sentience, 30(1). 